\title{
RELATOS DE PESQUISAS
GESTÃO DO CONHECIMENTO EM EMPRESA PÚBLICA:
PRÁTICAS E INICIATIVAS ADOTADAS PELO
POUPATEMPO
}

\author{
Ruggero Ruggieri \\ Mestre em Informática e Gestão do Conhecimento pela Universidade Nove \\ de Julho, Brasil. Coordenador de Projetos em Sistemas de Operação da \\ Prodesp/Poupatempo, Brasil. \\ E-mail: rruggieri@sp.gov.br \\ Marcos Antonio Gaspar \\ Doutor em Administração pela Universidade de São Paulo, Brasil. \\ Professor da Universidade Nove de Julho, Brasil. \\ E-mail: marcos.antonio@uni9.pro.br \\ Celia Hatsumi Aihara \\ Doutoranda em Informática e Gestão do Conhecimento pela Universidade \\ Nove de Julho, Brasil. Sócia da Adax Consultoria, Brasil. \\ E-mail:c.aihara@hotmail.com \\ Simone Martins Olivero \\ Mestre em Administração pela Universidade Nove de Julho, Brasil. \\ Coordenadora de Gestão do Conhecimento e Indicadores da \\ Prodesp/Poupatempo, Brasil. \\ E-mail: solivero@sp.gov.br
}

\section{Resumo}

O objetivo desta pesquisa é verificar quais práticas e iniciativas de Gestão do Conhecimento (GC) mais contribuíram para a efetivação da adoção, operacionalização e gestão da política de Gestão do Conhecimento e Inovação do Decreto n. 53.963/2009 (SÃO PAULO, 2009), que instituiu a Política de Gestão do Conhecimento e Inovação para as organizações públicas paulistas. Esta é uma pesquisa descritiva qualitativa que empregou como instrumentos de pesquisa roteiro de entrevista semiestruturada, observação direta e análise documental de registros públicos. Foram obtidas 32 respostas de gestores e 70 respostas de funcionários técnicos no Poupatempo. As principais práticas e iniciativas efetivadas pelo Poupatempo foram: a) alta prioridade dada à iniciativa no nível mais alto da hierarquia; b) comprometimento da alta administração e das chefias intermediárias; c) alocação de recursos financeiros suficientes; d) disseminação de exemplos de casos reais de implementação da GC que demonstrassem visibilidade e ajudassem a convencer os colaboradores; e) sinalização de que a GC e da informação são prioritários para a qualidade do programa; f) emprego de metodologias que guiassem o processo de implantação do modelo de GC e, por fim; g) concentração de esforços em tecnologia da informação e comunicações, em vez de questões gerenciais ou ligadas às pessoas. Além disso, ressalta-se a importância da implementação de uma política de gestão do conhecimento com diretrizes e estratégias claramente definidas, visando assim agilizar o processo de institucionalização da GC na Administração Pública do Poupatempo.

Palavras-chave: Gestão do conhecimento. Práticas de gestão do conhecimento. Conhecimento organizacional. Empresa pública.

Perspectivas em Gestão \& Conhecimento, João Pessoa, v. 11, número especial, p. 56-70, mar. 2021 DOI: http://dx.doi.org/10.22478/ufpb.2236-417X.2021v11nEspecial.57311

http://periodicos.ufpb.br/ojs2/index.php/pgc. ISSN: 2236-417X. Publicação sob Licença (cc)) EY-Nc-ND 


\title{
KNOWLEDGE MANAGEMENT IN A PUBLIC COMPANY:
} PRACTICES AND INITIATIVES ADOPTED BY POUPATEMPO

\begin{abstract}
The objective of this research is to verify which Knowledge Management (KM) practices and initiatives contributed most to the effective adoption, operationalization and management of the Knowledge and Innovation Management policy of Decree n. 53,963/2009 (SAO PAULO, 2009), which instituted the Knowledge and Innovation Management Policy for public organizations in Sao Paulo. This is a qualitative descriptive research that used semi-structured interviews, direct observation, and documentary analysis of public records as research tools. There were obtained 32 responses from managers and 70 responses of technical staff at Poupatempo. The main practices and initiatives implemented by Poupatempo were: a) high priority given to the initiative at the highest hierarchy's level; b) commitment from top management and middle managers; c) allocation of sufficient financial resources; d) dissemination of examples of real cases of $K M$ implementation that demonstrate visibility and help to convince employees; e) signaling that KM and information are a priority for the quality of the program; f) use of methodologies to guide the process of implementing the KM model and, finally; $g$ ) concentration of efforts in information and communications technology, instead of managerial or people-related issues. In addition, the importance of implementing a knowledge management policy with clearly defined guidelines and strategies is emphasized, thus seeking to streamline the process of institutionalizing KM in the Public Administration of Poupatempo.
\end{abstract}

Keywords: Knowledge management. Knowledge management practices. Organizational knowledge. Public company.

\section{INTRODUÇÃO}

O conhecimento tem sido um recurso cada vez mais valorizado pelas organizações atuantes na sociedade contemporânea. Além de sua importância para as empresas privadas, há também de se considerar sua relevância no contexto das organizações públicas. Nas organizações da esfera pública, o ritmo em geral é mais lento nos processos de mudanças. A maioria das organizações públicas não consegue responder com desenvoltura, pois ainda preserva características da administração pública, especialmente pela sua impossibilidade de se afastar das normas e instruções seguras e rígidas já conhecidas e experimentadas, não conseguindo assim responder com qualidade as demandas da sociedade (McEVOY; RAGAB; ARISHA, 2017).

Isto porque o modelo de administração ainda reinante nas organizações públicas foi preparado em uma época em que as mudanças aconteciam mais lentamente. Além disso, as transformações ocorriam com menor intensidade e rapidez. Ou seja, há de se considerar a nova contextualização da sociedade contemporânea inserida na Era do Conhecimento. Nesse novo contexto, o conhecimento é um recurso fundamental para as organizações públicas modernas, segundo indica Schlesinger (2008).

Nesse sentido, a Gestão do Conhecimento (GC) na esfera da Administração Pública, conforme indicam Pee e Kankanhalli (2016), parte do pressuposto de que as organizações públicas utilizam a Tecnologia da Informação (TI) para colaborar com outros agentes da sociedade. Isto porque verifica-se maior necessidade de desenvolver fortes capacidades de partilha, aplicação e criação de conhecimentos. Assim, as organizações públicas devem buscar promover condições para a contínua criação e disseminação de conhecimentos em prol da geração de benefícios para a sociedade (PEE; KANKANHALLI, 2016).

É importante que a administração pública esteja inserida na discussão dos conceitos da sociedade contemporânea e suas características, rompendo assim o bloqueio entre as

Perspectivas em Gestão \& Conhecimento, João Pessoa, v. 11, número especial, p. 56-70, mar. 2021. 
organizações públicas e as organizações privadas e outros agentes envolvidos. A importância da GC nesse contexto se sobressai e precisa estar incorporada à administração pública, em prol da melhoria de desempenho dessas organizações. Segundo McEvoy, Ragab e Arisha (2017), as estratégias de GC no contexto público são incompatíveis com as estratégias de uma organização privada, o que pode ser considerado um problema na implementação de iniciativas de GC em organizações do setor público (OSP). Além disso, os autores consideram ainda que restrições orçamentárias e a falta de reconhecimento dos gestores acerca da importância dos ativos do conhecimento também sejam grandes desafios para a adoção da GC em OSP.

No entanto, McEvoy, Ragab e Arisha (2017) afirmam que a observância da perspectiva de GC é inevitável para as organizações do setor público, ainda que a cultura de gestão pública tradicional seja mais burocrática e muitas vezes não suporte a plataforma recomendada para efetivar a GC em organizações. Na visão dos autores citados, a estrutura hierárquica rígida da administração pública, muitas vezes, cria barreiras em compartilhar conhecimentos e experiências com outros agentes envolvidos.

Assim, o conhecimento se firma como a matéria-prima fundamental para a criatividade que permite a recombinação, reestruturação e busca de novos conhecimentos e informações (OHLSSON, 2011). Consequentemente, por meio do intercâmbio de conhecimentos sem restrições, os funcionários podem efetivamente reunir e utilizar conhecimentos distribuídos entre indivíduos e unidades de trabalho, promovendo assim a identificação de soluções criativas a serem coletivizadas nas organizações (HANSEN, 2002).

Face ao contexto apresentado, o objetivo desta pesquisa é verificar quais práticas e iniciativas de GC mais contribuíram para a efetivação da adoção, operacionalização e gestão da política de Gestão do Conhecimento e Inovação do Decreto n. 53.963/2009 (SÃO PAULO, 2009).

\section{REFERENCIAL TEÓRICO}

\subsection{Gestão do Conhecimento}

Segundo os autores Cunha, Vasconcelos e Afonso (2010) a emergência do conceito de GC é resultante da vertente da administração focada na informação, por sua vez oriunda de dados. Assim, os autores destacam a seriedade em diferenciar epistemologias e conceitos sobre dados, informações e conhecimento. Conforme relato de Davenport e Prusak (2003), alguns pesquisadores utilizam outros termos como determinação, ação, sabedoria e insight, em paralelo a esses três conceitos básicos (dado, informação e conhecimento); contudo, os autores acreditam ser mais adequada a divisão apenas em dado, informação e conhecimento. Para se entender o que vem a ser informação e conhecimento é importante expor o que são dados e qual o seu papel nas organizações.

De acordo com Tidd e Bessant (2015) os dados podem ser compreendidos como um agrupamento de observações brutas, geralmente fácil de estruturar, gravar, armazenar e manipular eletronicamente. Já quanto à informação, Laudon e Laudon (2004) argumentam que as informações estão associadas aos processos de negócio da organização, consolidando o relacionamento de sistemas de informações com seus respectivos processos pertinentes. Assim, acentua-se a importância do foco nas informações necessárias para suportar os processos de negócios das diversas áreas da organização.

Considerando-se a evolução delineada até então quanto aos dados e às informações, Davenport e Prusak (2003) definem o conhecimento como sendo uma mistura fluída de experiência condensada, valores, informação contextual e insight experimentado, que proporciona uma estrutura para a avaliação e incorporação de novos ensaios e novas

Perspectivas em Gestão \& Conhecimento, João Pessoa, v. 11, número especial, p. 56-70, mar. 2021. 
informações. Para Tidd e Bessant (2015), o conhecimento é advindo da informação contextualizada, à qual foi atribuída significado que a torne relevante e de utilização mais simplificada. Os autores concluem que o conhecimento é mais valioso que a informação por incluir especialização, experiência, valores e insights estruturados.

Davenport e Prusak (2003) acreditam que o envolvimento das pessoas na transformação de informação em conhecimento é indispensável, uma vez que há de se considerar o entendimento destas por meio de suas experiências e aprendizado pessoal. Além disso, Popadiuk e Ricciadi (2011) e Nonaka e Takeuchi (1995) comentam sobre o conhecimento relacionado à confiança verdadeira e justificada, que se perfaz num processo eficaz de relevar a crença pessoal em relação à verdade. Na literatura são apresentadas categorizações do conhecimento, como tácito, explícito, sistemático, informal, codificável e não codificável. A maior parte dos pesquisadores da temática conhecimento prefere explorar a classificação entre tácito e explícito (NONAKA; TAKEUCHI, 1995), tipologia adotada nesta pesquisa.

O conhecimento explícito é mais simples de ser comunicado, visto que a sua facilidade de ser expresso através de dados, informações, documentos, gráficos, dados brutos, fórmulas científicas, procedimentos codificados ou princípios universais. A outra visão do conhecimento (tácito) é extremamente privado e difícil de formalizar, assim como o seu compartilhamento. Ele é constituído através do know-how subjetivo, sentimentos, insights, valores e individualização dos indivíduos (TIDD; BESSANT, 2015; CHOO, 2003; NONAKA; TAKEUCHI, 1995). A origem do conhecimento tácito repousa no indivíduo, ou seja, em suas experiências, crenças e aprendizagens acumuladas. Mas se esse conhecimento individual não for transmitido à organização, mantendo-se apenas em nível pessoal, será perdido em termos do contexto organizacional (NONAKA; TAKEUCHI, 1995).

Tatto e Bordin (2016) sustentam que o processo de construção do conhecimento diz respeito às crenças e compromissos envolvidos, estando essencialmente relacionado à ação, atitude e intenção específicas. Segundo Bubenko Junior, Persson e Stirna (2001), a padronização de conhecimentos é a forma de modelar um conhecimento organizacional, com o objetivo de permitir entender o funcionamento de uma forma específica de contemplar o mundo e que pode ser aplicada em várias vertentes do conhecimento de uma empresa ou de um processo do negócio. Tal ação tem capacidade de discernir coletivamente os conhecimentos, representando padrões de referência, experiências e conhecimento intrínseco dos participantes.

Outra abordagem para o conhecimento organizacional seria quanto à escolha e utilização adequada de tecnologia de informação, conforme estudado por Moreno e Santos (2012), Yoo et al., (2007) e Steil e Pacheco (2008), dada sua importância no processo de armazenamento das informações e dos conhecimentos. As ferramentas de tecnologia da informação indicadas pelos autores são capazes de fornecer uma infraestrutura de conhecimento que facilita a distribuição e trocas de conhecimento organizacional.

$\mathrm{Na}$ atual configuração da sociedade se explora o argumento de que o recurso básico da economia não é mais o capital, os recursos naturais ou o trabalho, mas sim o ativo denominado conhecimento (DRUCKER, 2002). Os profissionais que conseguem lidar melhor com o recurso conhecimento apresentam, em geral, vantagens sobre outros profissionais. Tal contexto também se reflete às organizações, quanto à sua capacidade de lidar com o ativo intangível denominado conhecimento.

A estruturação de uma tipologia de papéis do trabalhador do conhecimento proposta por Reinhardt et al. (2011, p. 9) surge do resultado de um tripé embasado numa perspectiva ação versus reação (conhecimento intensivo versus atividade versus execução). Ou seja, "os trabalhadores do conhecimento emergem de padrões de ações e interiorizam procedimentos e rotinas nas atividades de trabalhos do conhecimento". Nesse prisma, a importância da GC na Sociedade do Conhecimento pode ser resumida para a administração pública como a opção

Perspectivas em Gestão \& Conhecimento, João Pessoa, v. 11, número especial, p. 56-70, mar. 2021. 
por novas capacidades e práticas com grandes benefícios "para fortalecer a eficácia do serviço público e melhorar a sociedade em que atua" (WIIG, 2002, p. 3 [tradução nossa]).

Terra (2005) e Miranda, Tarapanoff e Duarte (2010) reforçam a importância do conhecimento na organização ao mencionarem o processo de GC e suas etapas, quais sejam: compartilhamento do conhecimento tácito, criação de conceitos, justificação de conceitos, construção de um protótipo e nivelamento transversal do conhecimento, conforme já mencionado anteriormente. Estudos demonstram que os processos de GC podem melhorar o desempenho do setor público com um impacto na capacidade inovativa, como também no desempenho operacional e melhoria na qualidade (AL AHBABI et al., 2019; BALASUBRAMANIAN et al., 2019).

O emprego do conhecimento enquanto ferramenta de trabalho requer a implantação das condições mínimas para tanto, de modo a permitir que fluxo do conhecimento entre os colaboradores envolvidos (SABBAG, 2009). Ou seja, na visão do autor, para que o conhecimento se torne um recurso organizacional relevante, é preciso que a organização saiba como gerir, criar e transferir conhecimentos. Assim, o conhecimento passou a ser um instrumento de trabalho em todos os segmentos, tornou-se mais clara a sua necessidade, tanto na iniciativa privada, como na iniciativa pública, tendo assim ganhado maior prioridade nas organizações contemporâneas.

\subsection{Gestão do Conhecimento nas Organizações Públicas}

Wiig (2002, p. 224) destaca a importância do conhecimento na administração pública, ao indicar que "a viabilização de qualquer sociedade depende da qualidade do fornecimento dos serviços públicos, sendo que essa qualidade é influenciada por fatores como estrutura governamental, responsabilidades, capacidades, informação, especialização do quadro de servidores e conhecimento disponível". Ainda segundo o autor, "é importante criar uma visão organizacional, que deve ser amplamente disseminada sobre o que a GC pode fazer em cada unidade da administração pública, com foco especial nos benefícios e impactos que podem ser esperados por essas novas práticas" (WIIG, 2002, p. 239).

A GC acontece de forma morosa na esfera pública quando comparada ao setor privado e, por isso, para prover o acesso à informação e ao conhecimento democraticamente, existe a necessidade de desenvolver infraestrutura, conteúdos e serviços (BRITO, MACEDO FILHO, 2017). Segundo Batista (2012, p. 10), "no setor público é importante relacionar também os processos de GC (identificação, criação, compartilhamento, armazenamento e aplicação do conhecimento) com a aprendizagem e a inovação, sendo que a inovação nas organizações públicas é voltada para o aumento da eficiência e para a melhoria da qualidade dos serviços públicos prestados à população". Na gestão Pública, a GC deve ser direcionada aos servidores públicos, que detêm o conhecimento, a alta gestão que tem o poder de fazer acontecer e aos cidadãos que são o público alvo do serviço público. Isto se dá por meio compartilhamento e armazenamento de informações, eficiência e a melhoria na qualidade dos serviços.

Heisig (2009) analisou 160 modelos de GC relevantes, tanto para organizações privadas como públicas, oriundos da pesquisa e da prática organizacional para classificar os componentes de GC e descobrir distinções e conformidades nos processos de GC (identificar, criar, armazenar, compartilhar e aplicar conhecimento) e nas dimensões de GC: i) Humana (categorias: cultura, pessoas e liderança); ii) Organização (categorias: estruturas e processos); iii) Tecnologia e iv) Gestão de processos (categorias: estratégia e controle), que são relevantes tanto para organizações privadas como públicas.

Abdullah e Date (2009) mencionam os seguintes motivos que os setores público e privado têm em comum ao implantar a GC na organização: i) atrair e manter o capital humano; ii) promover o capital social; iii) criar e usar o capital estrutural, iv) compartilhar processos e

Perspectivas em Gestão \& Conhecimento, João Pessoa, v. 11, número especial, p. 56-70, mar. 2021. 
melhores práticas (em combinação com práticas inovadoras), e v) estimular a colaboração. 0 setor público tem papel fundamental e único na promoção da partilha do conhecimento, na criação, na integração, e disseminação de recursos de conhecimento disponíveis em seu contexto. Este papel inclui: o fornecimento de conhecimento tradicionalmente não fornecido por empresas privadas; garantia de educação e conhecimento para todos; construção de centrais de conhecimento; e promoção de direitos de propriedade intelectual. Há de se considerar ainda que a aplicação do conhecimento no contexto público pode ser entendida também pela estrutura diferenciada da organização pública.

Assim, as características específicas de organizações públicas para impulsionar o conhecimento devem ser consideradas, quais sejam: (a) Conhecimento é um recurso inimitável e o governo eficaz deve basear-se na aquisição e divulgação eficazes de conhecimento; (b) Governo é equitativo, o que pressupõe que requisitos de conhecimento semelhantes sejam distribuídos entre estados e governos; (c) Transferências frequentes de trabalhadores do conhecimento através de departamentos (dreno de conhecimentos); e (d) Necessidade de se posicionar como um governo antecipatório, que aprende com a experiência passada, entende o cenário e antecipa futuras ameaças e oportunidades (ABDULLAH; DATE, 2009)

Pesquisas desenvolvidas por McAdams e Reid (2000) buscaram comparar percepções do setor público e privado quanto à GC praticada. Os resultados demonstraram que no setor público a GC foi mais desenvolvida como filosofia de gestão. Nesse sentido, foi observado que os quatro principais benefícios percebidos da GC foram: melhoria da qualidade, eficiência, aprendizagem da gestão e redução dos custos. Já Al Ahbabi et al. (2019) indicam que os impactos significativos dos processos de GC no desempenho da organização pública possam motivar a implementação no setor público.

Batista (2012, p. 14) comenta que "não é necessário construir um modelo específico de GC para a Administração Pública brasileira. Seria melhor, então, adotar um modelo teórico construído em organizações privadas e buscar moldá-lo às características específicas da organização pública". Alguns autores especialistas em GC discordam deste argumento, como Cong e Pandya (2003), que refletiram ser necessário um modelo genérico de GC especificamente voltado ao setor público, uma vez que as diferenças entre as organizações pública e privada modificam as características da implementação de estratégias baseadas em GC.

\subsection{Administração pública e empresa pública}

Para Meirelles (1996) entende a administração pública como o conjunto de órgãos instituídos para consecução dos objetivos do Governo; em sentido material, é o conjunto das funções necessárias aos serviços públicos em geral; em acepção operacional, é o desempenho perene e sistemático, legal e técnico, dos serviços do próprio Estado ou por ele assumido em benefício da coletividade. Numa visão global, a Administração Pública é todo o aparelhamento do Estado preordenado à realização de seus serviços, visando à satisfação das necessidades coletivas.

Do ponto de vista de Moraes (1999) a administração pública pode ser definida objetivamente como a atividade concreta e imediata que o Estado desenvolve para a consecução dos interesses coletivos, e ainda subjetivamente como o conjunto de órgãos e de pessoas jurídicas aos qual a lei atribui o exercício da função administrativa do Estado. Em vista dos conceitos explicitados, pode-se entender que a Administração Pública está ligada ao interesse público e às necessidades sociais, valendo-se, para isso, de toda a sua estrutura administrativa, direta ou indireta, como também das ferramentas que a legislação lhe permite

Perspectivas em Gestão \& Conhecimento, João Pessoa, v. 11, número especial, p. 56-70, mar. 2021. 
utilizar. Isto porque para cumprir a função administrativa, sempre direcionada ao interesse público, o Estado se vale de certas prerrogativas.

No caso da administração pública a vontade decorre da lei que fixa finalidade a ser perseguida pelos administradores, neste caso, mantidos com recursos públicos e encarregados da decisão e implementação das normas necessárias ao bem-estar social e das ações necessárias à gestão da coisa pública. Assim, a denominada função administrativa do Estado submete-se a um especial regime jurídico. Trata-se do denominado regime de direito público ou regime jurídico-administrativo. Sua característica essencial reside, de um lado, na admissibilidade da ideia de que a execução da lei por agentes públicos exige o deferimento de necessárias prerrogativas de autoridade, que façam com que o interesse público juridicamente predomine sobre o interesse privado; e de outro, na formulação de que o interesse público não pode ser livremente disposto por aqueles que, em nome da coletividade, recebem o dever-poder de realizá-los. Segundo a Constituição Federal de 1988, consiste, na verdade, no regime jurídico decorrente da conjugação de dois princípios básicos: "o princípio da supremacia dos interesses públicos e o da indisponibilidade dos interesses públicos".

Deste modo, os princípios inerentes à Administração Pública são aqueles expostos no art. 37 da Constituição (da legalidade, da impessoalidade, da moralidade, da publicidade e da eficiência) (BRASIL, 1988). Cabe acentuar que estes princípios se constituem mutuamente e não se excluem, e não são jamais eliminados na gestão pública. Destaca-se ainda que esses princípios forneçam as diretrizes a serem seguidas por todos os administradores públicos.

A aplicação das metodologias de GC na administração pública vai além dos objetivos de desenvolvimento organizacional, pois sua finalidade, conforme indica Batista (2004) é: “a) preparar cidadãos, e organizações para atuar como parceiros do Estado na elaboração e na implementação de políticas públicas; b) reduzir as desigualdades por meio de construção, manutenção e ampliação do capital intelectual das empresas; e c) criar uma sociedade competitiva por meio da educação dos cidadãos, e mediante o desenvolvimento das organizações para que estas se tornem competitivas em todas as áreas do conhecimento" (BATISTA, 2004, p.10).

A administração pública pode contar com empresas públicas para a consecução de seus objetivos. Empresas públicas são entidades definidas no direito positivo brasileiro como sendo dotadas de personalidade jurídica de direito privado. Elas são criadas pelo poder público para desempenhar as atividades necessárias à conquista de fins de natureza pública, mas devem funcionar de acordo com os moldes e padrões que caracterizam as atividades dos particulares (DALLARI, 1979).

O surgimento das organizações públicas representou uma mudança nos paradigmas da sociedade. A importância delas deve-se principalmente ao fato de serem responsáveis pela mediação entre o Estado e a sociedade. Sobre o fator público, entendeu-se recentemente que todas as organizações pertencem à mesma espécie: todas são organizações e, por isso, guardam algumas características comuns. Todas teriam, em última instância, uma finalidade pública (VENTURA,1999).

Na visão de Vaitsman (2000), enquanto produto de uma história social, política e cívica a configuração de qualquer organização pública também revela determinados padrões de interações entre seus membros. Se por cultura organizacional entende-se o sistema de significados compartilhados pelos membros de uma organização que lhes dá algum tipo de identidade coletiva, a cultura das organizações públicas é marcada pelo modo como se instituíram as relações entre estado e sociedade, bem como as relações do sujeito com a coisa pública.

Perspectivas em Gestão \& Conhecimento, João Pessoa, v. 11, número especial, p. 56-70, mar. 2021. 


\section{MÉTODO E MATERIAIS}

Este é um estudo descritivo de natureza qualitativa, que considera como método a ênfase na perspectiva do indivíduo que está sendo estudado e no ambiente em que ele está inserido. As pesquisas descritivas, como o próprio nome indica, procuram descrever sistematicamente uma situação, problema, fenômeno ou serviço (KUMAR, 2011). A pesquisa qualitativa é um campo de investigação que cruza disciplinas, campos e assuntos com uma complexa e interligada família de termos e conceitos (DENZIN; LINCOLN, 2018).

Num primeiro momento foi executada pesquisa bibliográfica com base na temática GC na Administração Pública, junto às bases de dados Google Scholar, Proquest e Periódicos CAPES. Tais bases de dados foram escolhidas por incluírem publicações acadêmicas multidisciplinares, conforme a natureza da temática envolvida na presente pesquisa.

Nesta pesquisa foram adotadas as seguintes técnicas de levantamento: a) entrevistas semiestruturadas, b) observação direta e c) análise documental de registros públicos. Este estudo descritivo qualitativo considerou como método de pesquisa o levantamento de informações junto à empresa Poupatempo do Estado de São Paulo. O Poupatempo foi selecionado como principal objeto de pesquisa em função de ser uma empresa pública paradigmática. O Poupatempo ganhou várias premiações nos últimos anos, além de ser reconhecido como uma empresa de prestação de serviços de elevada qualidade pela população (SÃO PAULO, 2014, 2017).

Para tanto foi adotado o estudo de casos desta importante empresa pública paulista. Assim, pretendeu-se verificar quais práticas e iniciativas de GC mais contribuíram para a efetivação da adoção, operacionalização e gestão da política de Gestão do Conhecimento e Inovação do Decreto n. 53.963/2009 (SÃO PAULO, 2009), que instituiu a Política de Gestão do Conhecimento e Inovação para as organizações públicas paulistas. O método empregado nesta pesquisa (estudo de casos), segundo Yin (2015) facilita a compreensão do objeto a ser estudado, no caso o Poupatempo no âmbito do total de unidades de atendimento, num contexto organizacional, social e político.

Assim, esta pesquisa realizou estudo de casos para abordar os objetivos de pesquisa propostos junto aos gestores e profissionais de algumas unidades operacionais da empresa pública Poupatempo. Foram realizadas consultas junto aos profissionais das unidades selecionadas, de acordo com o nível de atendimento indicados pelas equipes do Poupatempo. Assim, os gestores selecionados, além de responderem ao roteiro de entrevista estabelecido, também encaminhavam o instrumento de pesquisa aos seus respectivos funcionários operacionais das unidades Poupatempo selecionadas. A quantidade de respostas às entrevistas variou nas diferentes unidades do Poupatempo pesquisadas, devido principalmente à quantidade de funcionários da área de atendimento e ao nível de experiência/conhecimento quanto às práticas de GC.

Foram executadas entrevistas junto aos gestores da área de Administração Geral e Administração da GC com seguintes perfis profissionais: especialistas de suporte e gestão, analistas de suporte e gestão, analistas de suporte em informática, técnicos administrativos em gestão, coordenadores de atendimento, coordenadores de recursos internos, assistentes administrativos, coordenadores de atendimento e arquitetos. As entrevistas aplicadas aos profissionais versavam sobre a análise da GC implementada no Poupatempo, segregado em duas partes: a primeira parte voltava-se às iniciativas para adoção, operacionalização e gestão da política de GC e inovação, e a segunda parte voltava-se às práticas e iniciativas de criação e disseminação de conhecimento.

0 roteiro de entrevista semiestruturada foi desenvolvido a partir do referencial teórico construído, tendo com principais bases os trabalhos de Batista et al. (2005) e Gaspar (2010). 0

Perspectivas em Gestão \& Conhecimento, João Pessoa, v. 11, número especial, p. 56-70, mar. 2021. 
roteiro foi aplicado ao gestor de GC da Superintendência do Poupatempo, aos gestores das unidades Poupatempo selecionadas e aos técnicos administrativos das respectivas unidades.

Quanto à observação direta, os pesquisadores tiveram acesso às unidades Poupatempo indicadas para verificar in loco o processo, as práticas e as iniciativas de GC utilizadas. A técnica de observação direta permite ao pesquisador não apenas "ver e ouvir, mas também [...] examinar fatos ou fenômenos que se deseja estudar" (MARCONI; LAKATOS, 2010 , p. 107). Já em relação à pesquisa documental, os pesquisadores tiveram acesso a documentos oficiais internos do Poupatempo (site, relatórios, estudos, intranets, documentação de atendimento, AVA avaliações e documentos quantitativos), bem como também se valeram de notícias publicadas em outros veículos de comunicação.

Em relação às técnicas de coleta e tratamento dos dados coletados na pesquisa de campo, as falas dos respondentes das entrevistas aplicadas foram documentadas e apreciadas a partir da técnica de análise de conteúdo de Bardin (2011), buscando-se assim compreender melhor o fenômeno estudado a partir dos objetivos formulados nesta pesquisa.

As informações das respostas coletadas por meio do roteiro de entrevista foram organizadas, tabuladas e codificadas, servindo também de base para a análise e compreensão dos principais achados com base nos objetivos traçados nesta proposta de pesquisa.

O conteúdo dos documentos considerados na pesquisa documental foi analisado visando depuração das informações no sentido de atender os objetivos de pesquisa já delineados. Segundo Gil (2008), os documentos constituem importante fonte de dados para a pesquisa, pois são fonte análise que pode proporcionar compreensão sobre o fenômeno em análise.

\section{APRESENTAÇÃO E DISCUSSÃO DOS RESULTADOS}

Todas as práticas e iniciativas de GC prospectadas na pesquisa de campo obtiveram, na opinião dos respondentes, elevada contribuição à efetivação da GC no Poupatempo. No caso analisado, as práticas e iniciativas de GC que foram assinaladas como 'contribui fortemente' ou 'contribui' receberam ao menos $75 \%$ das indicações dos sujeitos pesquisados, conforme indicado nas Tabelas 1 e 2.

A Tabela 1 expõe as principais iniciativas voltadas à adoção, operacionalização e gestão da política de GC e inovação.

Tabela 1 - Iniciativas voltadas à adoção, operacionalização e gestão da política de GC e inovação

\begin{tabular}{l|c|}
\hline \multicolumn{1}{c|}{ Iniciativas de GC } & $\begin{array}{l}\text { Somatória de respostas } \\
\text { ('contribui fortemente' } \\
\text { e 'contribui') }\end{array}$ \\
\hline Alta prioridade dada à iniciativa no nível mais alto da hierarquia & $100,0 \%$ \\
\hline $\begin{array}{l}\text { O comprometimento da alta administração e das chefias intermediárias } \\
\text { fazem a diferença para a promoção da GC }\end{array}$ & $96,9 \%$ \\
\hline Alocação de recursos financeiros suficientes & $90,6 \%$ \\
\hline $\begin{array}{l}\text { Disseminação de exemplos de casos reais de implementação da GC que } \\
\text { demonstram visibilidade e ajudam a convencer }\end{array}$ & $90,6 \%$ \\
\hline $\begin{array}{l}\text { A Gestão do Conhecimento e da informação são prioritários para a } \\
\text { qualidade do Programa }\end{array}$ & $90,6 \%$ \\
\hline $\begin{array}{l}\text { Metodologias que guiem o processo (inclusive a implantação do Modelo } \\
\text { de GC) }\end{array}$ & $87,6 \%$ \\
\hline $\begin{array}{l}\text { A organização tende a concentrar esforços na tecnologia da informação } \\
\text { e comunicações, em vez de questões gerenciais ou ligadas às pessoas }\end{array}$ & $56,2 \%$ \\
\hline
\end{tabular}

Fonte: Autores da pesquisa (2020)

Perspectivas em Gestão \& Conhecimento, João Pessoa, v. 11, número especial, p. 56-70, mar. 2021. 
Conforme resultados indicados na Tabela 1, verifica-se que a empresa pública Poupatempo empregou práticas e iniciativas de GC para adequar-se à adoção, operacionalização e gestão da política de gestão do conhecimento e inovação especificada no Decreto n. 53.963/2009 (SÃO PAULO, 2009). A implementação de tais práticas e iniciativas de GC foram, portanto, imprescindíveis à adequação do Poupatempo à legislação indicada.

A Tabela 2 expõe outras práticas e iniciativas indicadas pelos respondentes que foram desenvolvidas e empregadas na criação e disseminação de conhecimento na empresa pública Poupatempo.

Tabela 2 - Práticas de iniciativas de GC empregadas na criação e disseminação de conhecimento no Poupatempo

\begin{tabular}{|c|c|}
\hline Iniciativas de GC & $\begin{array}{l}\text { Somatória de respostas } \\
\text { ('contribui fortemente' } \\
\text { e 'contribui') }\end{array}$ \\
\hline Gestão por competências & $96,9 \%$ \\
\hline Mapeamento de competências & $96,9 \%$ \\
\hline Mapeamento de conhecimentos & $96,9 \%$ \\
\hline Estratégia declarada de GC & $93,8 \%$ \\
\hline Repositório de melhores práticas & $93,8 \%$ \\
\hline Rede de especialistas & $93,7 \%$ \\
\hline Benchmarking de conhecimentos & $90,6 \%$ \\
\hline Espaços e eventos dedicados à socialização dos conhecimentos & $90,6 \%$ \\
\hline Banco de conhecimentos & $90,6 \%$ \\
\hline Desenvolvimento de ações de Business Intelligence (BI) & $90,6 \%$ \\
\hline Treinamentos virtuais com a presença de instrutores online & $90,6 \%$ \\
\hline Multiplicadores de conhecimentos & $87,6 \%$ \\
\hline Mapeamento de processos & $87,6 \%$ \\
\hline Portal corporativo ou de departamentos & $87,6 \%$ \\
\hline Políticas declaradas de GC & $87,5 \%$ \\
\hline Plano de sucessão de GC & $87,5 \%$ \\
\hline Disponibilização de treinamentos presenciais com instrutores & $87,5 \%$ \\
\hline Disponibilização de comunicação corporativa para a GC & $84,4 \%$ \\
\hline Centro de competências & $84,4 \%$ \\
\hline Repositório de lições aprendidas & $84,4 \%$ \\
\hline Sistema de avaliação de processos de conhecimento & $84,4 \%$ \\
\hline Gestão de conteúdo & $84,4 \%$ \\
\hline $\begin{array}{l}\text { Desenvolvimento de ações de mentoring (tutoria no desenvolvimento } \\
\text { da carreira) para a formação de líderes voltados à GC (ou não) }\end{array}$ & $81,3 \%$ \\
\hline Propriedade intelectual oriunda da GC & $81,3 \%$ \\
\hline Mapas de conhecimentos & $81,3 \%$ \\
\hline $\begin{array}{l}\text { Cargos de CKO ou CKM (Chief Knowledge Officer ou Chief of Knowledge } \\
\text { Management - Gestor de GC) }\end{array}$ & $81,2 \%$ \\
\hline Área interna especifica para a GC & $81,2 \%$ \\
\hline Ações de educação corporativa & $81,2 \%$ \\
\hline Gestão de conteúdo dos conhecimentos - Ontologia ou taxonomia & $81,2 \%$ \\
\hline Comunidades de prática & $78,2 \%$ \\
\hline Reprodução de histórias (Story Telling) & $78,2 \%$ \\
\hline Aplicações para gestão de conhecimentos & $78,2 \%$ \\
\hline Ações de inteligência competitiva & $78,2 \%$ \\
\hline Repositório de documentos / biblioteca corporativa (física ou eletrônica) & $78,2 \%$ \\
\hline Universidade corporativa & $78,2 \%$ \\
\hline Sumarização ou inventários de conhecimentos & $78,2 \%$ \\
\hline Patentes oriundas da GC & $75,0 \%$ \\
\hline
\end{tabular}

Perspectivas em Gestão \& Conhecimento, João Pessoa, v. 11, número especial, p. 56-70, mar. 2021. 
Fonte: Autores da pesquisa (2020)

Os resultados expostos na Tabela 2 evidenciam que, além das práticas e iniciativas de GC implementadas inicialmente para adequação à política de gestão do conhecimento e inovação especificada no Decreto n. 53.963/2009 (SÃO PAULO, 2009), outras práticas também foram sendo implementadas posteriormente. Estes resultados demonstram a evolução da GC no Poupatempo, evidenciando assim a expansão da implementação de novas práticas e outras iniciativas voltadas ao gerenciamento dos conhecimentos na empresa.

Entretanto, algumas práticas e iniciativas obtiveram resultados abaixo dos $75 \%$ de concordância dos profissionais que participaram da pesquisa de campo, caracterizando-se como exceções na implantação da GC na empresa, conforme indicadas abaixo:

- 'Páginas amarelas internas' (56,3\%).

- 'Planos de carreira voltados ao desenvolvimento da GC' $(65,6 \%)$;

- 'Sistema de reconhecimento e recompensa por GC' (65,6\%);

- 'Desenvolvimento de ações de coaching (tutoria no desenvolvimento de competências) para formação de líderes voltados à GC (ou não)' (65,6\%);

\section{CONCLUSÕES}

$\mathrm{Na}$ sociedade contemporânea o conhecimento tem sido um recurso cada vez mais valorizado pelas organizações modernas. Além de sua importância para as empresas privadas, há também de se considerar sua relevância no contexto das organizações públicas. Nas empresas da esfera pública, em especial, o processo de mudança caminha em um ritmo mais lento, o que faz com que a organização pública demore mais para responder com agilidade e qualidade as demandas da sociedade. A GC pode auxiliar as empresas públicas a serem mais ágeis ao atender tais demanda com qualidade.

É necessário, portanto, que o Estado utilize práticas gerenciais modernas, sem perder de vista sua função eminentemente pública de sua atuação. Neste sentido, a implementação do Programa atualmente denominado Poupatempo de Atendimento ao Cidadão, objeto desta pesquisa, é diferenciado à medida em que tornou possível prestar serviços com qualidade à população. Esse programa vem servindo de modelo a outros órgãos da administração estadual de São Paulo e a outros setores da administração pública.

A proposta desta pesquisa foi verificar quais práticas e iniciativas de GC mais contribuíram para a efetivação da adoção, operacionalização e gestão da política de Gestão do Conhecimento e Inovação do Decreto n. 53.963/2009 (SÃO PAULO, 2009), que instituiu a Política de Gestão do Conhecimento e Inovação para as organizações públicas paulistas. Assim, a pesquisa buscou associar o objeto ao contexto para analisar a forma como se dá a GC nesta organização pública, analisando-se as práticas e iniciativas empregadas por esta organização.

A importância da GC implementada nas unidades do Poupatempo foi um recurso essencial, que pôde ser confirmado pelas respostas dos profissionais pesquisados. Os respondentes, de forma geral, consideraram as práticas e iniciativas pesquisadas um recurso fundamental na formação do conhecimento e na GC na organização. Além disso, os respondentes consultados também consideram a sua utilização um caminho essencial para a disseminação da informação e conhecimento na prestação de serviço de elevada qualidade ao cidadão. De forma geral, os respondentes afirmam que não veem mais o Poupatempo sem a utilização das práticas e iniciativas de GC, menção enfatizada pelos funcionários técnicos pesquisados que reforçaram a importância da disseminação do conhecimento para a operacionalização de suas tarefas de atendimento ao cidadão.

Perspectivas em Gestão \& Conhecimento, João Pessoa, v. 11, número especial, p. 56-70, mar. 2021. 
O modelo constituído pelo Poupatempo é válido para todo o Estado de São Paulo e prevê os princípios, diretrizes, normas, procedimentos, contratos e principais indicadores de análise de desempenho das Unidades para aferimento de performance.

A presente pesquisa tem como principais contribuições à Academia, a identificação de práticas e iniciativas de sucesso na GC em empresa pública, consideradas suas características específicas. Além disso, a presente pesquisa também gera contribuições aos gestores de empresas públicas quanto às práticas e iniciativas de GC a serem implementadas nas organizações públicas, visando maior probabilidade de sucesso em sua aplicação.

As limitações desta pesquisa voltam-se ao estudo de uma única empresa pública, não obstante o reconhecimento da qualidade dos serviços por ela prestados. Assim, os resultados auferidos não podem ser generalizados a outras organizações públicas. A presente pesquisa efetivou um recorte temporal no primeiro semestre de 2019, o que também representa uma limitação nos resultados auferidos.

Como sugestões de pesquisas futuras, indica-se a aplicação do protocolo e instrumentos desta pesquisa junto a outras empresas públicas, situadas em outros estados, bem como atuantes em outros setores. Também se sugere a efetivação de pesquisa considerando-se as ferramentas de Tecnologia da Informação voltadas à GC praticadas por empresas públicas.

\section{REFERÊNCIAS}

ABDULLAH, K.; DATE, H. Public sector knowledge management, a generic framework. Public Sector ICT Management Review, v. 3, n. 1, p. 1-14, Jan.-Jun. 2009.

AL AHBABI, S.A.; SINGH S.K.; BALASUBRAMANIAN S.; GAUR S.S. Employee perception of impact of knowledge management processes on public sector performance. Journal of Knowledge Management. v. 23, n. 1, 2019.

BALASUBRAMANIAN S, AL-AHBABI S, SREEJITH S. Knowledge management processes and performance. International Journal of Public Sector Management. v. 33, n. 1, p. 1-21, 2019.

BARDIN, L. Análise de conteúdo. São Paulo: Edições 70, 2011.

BATISTA, F. F. Governo que aprende gestão do conhecimento em organizações do executivo federal. 1022 ed. Brasília: Ipea, 2004, p. 10-104.

BATISTA, F. F. Modelo de gestão do conhecimento para a administração pública brasileira: como implementar a gestão do conhecimento para produzir resultados em benefício do cidadão. Brasília: Ipea, 2012.

BATISTA, F. F.; QUANDT, C. O.; PACHECO, F. F.; TERRA, J. C. C. Gestão do conhecimento na administração pública. Brasília: Ipea, 2005.

BRASIL. Constituição Federal de 05 de outubro de 1988. Constituição da República Federativa do Brasil de 1988. Brasília, 05 out. 1988.

Perspectivas em Gestão \& Conhecimento, João Pessoa, v. 11, número especial, p. 56-70, mar. 2021. 
BRITO, A. A. F. de.; MACEDO FILHO, D. R. de. A importância do modelo de gestão do conhecimento na administração pública. Revista Científica Multidisciplinar Núcleo do Conhecimento, v. 01, n. 07, p. 77-88, out. 2017.

BUBENKO JUNIOR, J.; PERSSON, A.; STIRNA, J. User guide of the knowledge management approach using enterprise knowledge patterns. Royal Institute of Technology, v. 1, n. 1, p. 152, out. 2001.

CHOO, C. W. A organização do conhecimento: como as organizações usam a informação para criar significado, construir conhecimento e tomar decisões. São Paulo: Senac, 2003.

CONG, X; PANDYA, K. V. Issues of knowledge management in the public sector. The Electronic Journal of Knowledge Management, v. 1, p. 25-33. 2003.

CUNHA, C.; VASCONCELOS, M. C; AFONSO, T. Análise das práticas de gestão do conhecimento de empresas do setor farmacêutico no Brasil. Revista Gestão \& Tecnologia, v. 7, n. 2, p. 1-14, dez. 2010.

DALLARI, A. A. Controle político das empresas públicas. Revista de Administração de Empresas, v. 7, p. 87-98. set. 1979.

DAVENPORT, T.; PRUSAK, L. Conhecimento empresarial: como as organizações gerenciam o seu capital intelectual. Rio de Janeiro: Campus, 2003.

DENZIN, N. K.; LINCOLN, Y. S. Handbook of qualitative research. 5 ed. Los Angeles: SAGE, 2018.

DRUCKER, P. Managing for the future: The 1990's and beyond. New York: Truman Tally Books/Dulton, Palo Alto: Stanford University. 2002.

GASPAR, M. A. Gestão do conhecimento em empresas atuantes na indústria de software no Brasil: um estudo das práticas e suas influências na eficácia empresarial. 223 f. Tese (Doutorado em Administração). Universidade de São Paulo, São Paulo, 2010.

GIL, A. C. Métodos e técnicas de pesquisa social. 6. ed. São Paulo: Atlas, 2008.

HANSEN, M. T. Knowledge networks: explaining effective knowledge sharing in multiunit companies. Organization Science, v. 1, n. 13, p. 223-353, jun. 2002.

HEISIG, P. Harmonization of knowledge management - comparing $160 \mathrm{KM}$ frameworks around the globe. Journal of Knowledge Management. v. 13, p. 4-31. 2009.

KUMAR, R. Research methodology: a step-by-step guide for beginners. 3 ed. London: Sage, 2011.

LAUDON, K.; LAUDON, J. Sistemas de informação gerenciais: administrando a empresa digital. São Paulo: Prentice Hall, 2004.

MARCONI, M. de A.; LAKATOS, E. M. Fundamentos de metodologia científica. 7 ed. São Paulo: Atlas, 2010.

Perspectivas em Gestão \& Conhecimento, João Pessoa, v. 11, número especial, p. 56-70, mar. 2021. 
McADAMS, R.; REID, R. A comparison of public and private sector perceptions and use of knowledge management. Journal of European Industrial Training. v. 24, n. 6, p. 317-329, 2000.

McEVOY, P., RAGAB, M. A., ARISHA, A. Review on the KM Applications in public organisations. The Electronic Journal of Knowledge Management, v. 5, n. 3, p. 37-48, 2017.

MEIRELLES, H. L. Direito administrativo brasileiro. 23. ed. São Paulo: Finanças Municipais, 1996.

MIRANDA, R. C. de R.; TARAPANOFF, K.; DUARTE, G. A. Criação de comunidades de prática como instrumento para o aprendizado organizacional. Revista Eletrônica de Estratégia \& Negócios, v. 3, n. 1, p.1-122, jun. 2010.

MORAES, A. de. Os 10 anos da Constituição Federal. São Paulo: Atlas, 1999.

MORENO, V.; SANTOS, L. H. A. dos. Gestão do conhecimento e redesenho de processos de negócio: proposta de uma metodologia integrada. Perspectivas em Ciência da Informação, São Paulo, v. 17, n. 1, p. 203-230, mar. 2012.

NONAKA, I.; TAKEUCHI, H. Criação de conhecimento na empresa: como as empresas japonesas geram a dinâmica da inovação. 20 ed. São Paulo: Elsevier, 1995.

OHLSSON, S. Deep learning: how the mind overrides experience. Cambridge: Cambridge University Press, 2011.

PEE, L. G.; KANKANHALLI, A. Interactions among factors influencing knowledge management in public-sector organizations: A resource-based view. Government Information Quarterly, v. 33, n. 1, p. 188-199, jan. 2016.

POPADIUK, S.; RICCIARDI, G. Conversão do conhecimento é fonte de vantagem competitiva sustentável? Uma análise empírica sob a perspectiva da resource-based view. Gest. Prod., v. 18, n. 1, p. 193-204, fev. 2011.

POUPATEMPO. Poupatempo. São Paulo: Poupatempo, 1996. Disponível em: https://www.POUPATEMPO.sp.gov.br/. Acesso em: 08 out. 2017.

REINHARDT, W. Knowledge worker roles and actions - Results of two empirical studies. Knowledge and Process Management, v. 18, n. 3, p. 09-10, 2011.

SABBAG, P. Y. Gerir projetos requer gerir conhecimentos. Revista Mundo Project Management, v. 27, p. 5-16, Jun. 2009.

SÃO PAULO. Decreto no 53.963, de 2009. Política de gestão do conhecimento e inovação. São Paulo: ALESP, 21 jan. 2009. p. 4.

SÃO PAULO. Poupatempo recebe prêmio LIDE de gestão pública. São Paulo: Portal do Governo do Estado de São Paulo, 2014.

Perspectivas em Gestão \& Conhecimento, João Pessoa, v. 11, número especial, p. 56-70, mar. 2021. 
SÃO PAULO. Metrô e Poupatempo recebem prêmios do Instituto Datafolha. São Paulo: Portal do Governo do Estado de São Paulo, 2017.

SCHLESINGER, C. C. B. Gestão do conhecimento na administração pública. Curitiba: IMAP, 2008.

STEIL, A. V.; PACHECO, R. Aprendizagem organizacional e criação de conhecimento - em um instituto privado de ciência e tecnologia. Revista Eletrônica de Estratégia \& Negócios, v. 1, n. 2, p. 25-46, 2008.

TATTO, L.; BORDIN, R. Filosofia e gestão do conhecimento: um estudo do conhecimento na perspectiva de Nonaka e Takeuchi. Cadernos EBAPE.BR, v. 14, n. 2, p. 340-350, 2016.

TERRA, J. C. C. Gestão do conhecimento: grande desafio empresarial. São Paulo: Negócio, 2005.

TIDD, J.; BESSANT, J. Gestão da Inovação. 5. ed. Porto Alegre: Bookman, 2015.

VAITSMAN, J. Cultura de organizações públicas de saúde: notas sobre a construção de um objeto. Caderno de Saúde Pública, v. 16, n. 3, p. 847-850, set. 2000.

VENTURA, E. C. F. Responsabilidade social das organizações: estudo de caso no Banco Central do Brasil. 164 f. Dissertação (Mestrado em Administração Pública) - Fundação Getúlio Vargas, Escola Brasileira de Administração Pública, Rio de Janeiro, 1999.

YIN, R. K. Estudo de caso: planejamento e métodos. 5. ed. Porto Alegre: Bookman, 2015.

YOO, K.; SUH, E.; KIM, K-Y. Knowledge flow-based business process redesign: applying a knowledge map to redesign a business process. Journal of Knowledge Management, v. 11, $n$. 3, p. 104-125, 2007.

WIIG, K. Knowledge management in public administration. Journal of Knowledge Management, v. 6, n. 3, p. 224-239, 2002.

Recebido em/Received: 25/01/2021 | Aprovado em/Approved: 22/02/2021

Perspectivas em Gestão \& Conhecimento, João Pessoa, v. 11, número especial, p. 56-70, mar. 2021. 